\title{
Economic and Hypothetical Dictator Game Experiments: Incentive Effects at the Individual Level
}

\author{
Avner Ben-Ner ${ }^{1}$ and Ori Levy ${ }^{2}$
}

November 2004

\begin{abstract}
The paper compares behavior in economic dictator game experiments played with actual money (amounts given by "dictator" subjects) with behavior in hypothetical dictator game experiments where subjects indicate what they would give, although no money is actually exchanged. The average amounts transferred in the two experiments are remarkably similar. Moreover, we uncover meaningful individual differences in real and hypothetical allocations and demonstrate the importance of two personality traits - agreeableness and extraversion - in reconciling them. We conclude that extraverts are "all talk;" agreeable subjects are "for real."
\end{abstract}

Keywords: Dictator Game, Incentives, Individual Differences, Personality. JEL Classification: C91, D81.

PT $^{1}$ TPIndustrial Relations Center, Carlson School of Management, University of Minnesota.

PT $^{2}$ TPDepartment of Finance, Carlson School of Management, University of Minnesota and the Economics Department, University of Haifa, ISRAEL. 
"The superior man is modest in his speech, but exceeds in his actions." - Confucius

"I have long since come to believe that people never mean half of what they say, and that it is best to disregard their talk and judge only their actions"

$$
\text { - Dorothy Day }
$$

\section{Introduction}

Economic experiments are usually carried out with actual money in the belief that subjects act truthfully only if their decisions and actions have actual rather than hypothetical financial consequences for them. Whether money is required to elicit subjects' preferences in experiments is an important practical question for experimenters. Indeed, financial incentives often fail to bring about a clear improvement in subjects' mean performance (Camerer and Hogarth (1999) survey the evidence). On the other hand, in studies with "Dictator Games," zero-sum, one-shot games, where subjects are invited to consider sharing a fixed endowment with another person who is entirely passive, incentives are claimed to affect (as opposed to "improve," since there is no accepted performance metric) behavior. In particular, when payments are real rather than hypothetical, subjects were found to act less generously, keeping more to themselves (Sefton (1992) and Forsythe et al. (1994)).

This paper compares behavior in economic dictator game experiments played with actual money (amounts given by "dictator" subjects) with behavior in hypothetical dictator game experiments where subjects indicate what they would give, although they would not actually be asked to do so. Experimental subjects are allowed to split $\$ 10$ with a person of known gender. ${ }^{3}$ When we aggregate across recipients and compare the allocations made in the two experiments, we are unable to

PT $^{3}$ TPHolm (2000) and Ben-Ner, Kong, and Putterman (2004) informed subjects of the recipient's gender. Fershtman and Gneezy (2001) informed subjects of the recipient's ethnic affiliation. 
find significant differences in subjects' generosity in the two experiments. Amounts given by the average subject do not depend on the presence of financial incentives.

While the observation that average amounts sent in real and hypothetical experiments are statistically indistinguishable may be interesting, it potentially fails to recount the whole story since possible individual heterogeneity is ruled out by construction. In this paper, we challenge the commonly-made assumption of a fictitious "representative" subject, imposed by aggregating experimental data across subjects, and turn to investigate real and hypothetical allocations at the individual level. Despite the fact that allocations in the two experiments are on average identical, we document systematic individual differences in discrepancies between hypothetical and actual transfers of money. As part of the experiment, all subjects complete a self-report inventory measuring five major personality factors: neuroticism, extraversion, openness to experience, agreeableness, and conscientiousness. Based on information from these tests, observed gaps in real versus hypothetical transfers are successfully accounted for by this five-factor model of personality. So, while certain personality types tend to exaggerate their actual contributions when doing so is inconsequential financially, other types will understate it, doing more than just "putting their money where their mouths are."

The study of incentive effects in dictator game experiments at the individual level and the possible relations to corresponding measurable personality types supplements recent empirical evidence on the importance of disaggregation across individuals. For example, it is argued that the significant variance in observed decision biases can be accounted for by various measures of cognitive ability (Stanovich (1999)). The question whether cognitive ability is (partly) "responsible" for affecting money allocation decisions when financial consequences are real rather 
than hypothetical is an empirical one. Since subjects complete a cognitive ability test as part of the experiment, we will be able to shed light on the role of sophistication in this particular setting (i.e., do more sophisticated subjects behave in a more socially desirable way when doing so is costless?).

More closely related to the present study, Boone et al. (1999) document relationships between observed behavior in the "Prisoner's Dilemma" and four personality traits (locus of control, self-monitoring, type-A behavior, and sensation seeking). Personality characteristics also appear to play a role in the determination of optimal consumption levels in a dynamic setting (Brandstatter and Guth (2000)), shaping risk preferences (Lauriola and Levin (2001)), affecting the degree of trust and trustworthiness in "trust game" experiments (Gunnthorsdottir et al. (2002) and Burks et al. (2003)), determining individual sending behavior and degree of reciprocity in "dictator game" experiments (Ben-Ner, Kong, and Putterman (2004) and Ben-Ner, Putterman, Kong, and Magan (2004)), affecting the degree of overconfidence (Campbell et al. (2004)), influencing portfolio allocations between relatively risky and safe investment opportunities (Hunter and Kemp (2004)), and are responsible in part for observed variations in earnings in the labor market (Nyhus and Pons (2004)).

The rest of the paper proceeds as follows. Section 2 describes the conventional and hypothetical dictator game experiments. Section 3 presents our analysis and results. Section 4 summarizes our findings and presents concluding remarks. 


\section{The Experiment}

\subsection{Conventional Economic Dictator Game Experiments}

On two separate occasions, all freshmen at the University of Minnesota (approximately 5,000) were invited by e-mail to participate in economic-psychological experiments to take place on a Friday about one month after the beginning of the academic year. The e-mail invitations were issued individually (the identities of other recipients were not disclosed in the invitation), and requested their participation in an economics/psychology experiment that would last up to two hours, that would require no physical effort, that would assure subjects' anonymity, and that would earn them a $\$ 15$ participation fee. On both occasions, nearly $10 \%$ of the students responded, and about half of those actually participated. The first set of experiments consisted of conventional economic dictator game experiments with $\$ 10$ endowments of actual money. The invitation to this experiment mentioned that subjects may earn additional money. Part of this experiment was replicated at Brown University. The second set of experiments consisted of simulated dictator game experiments conducted with hypothetical $\$ 10$ endowments (see below).

In both experiments, subjects were also asked to complete a set of cognitive ability (Wonderlic) and personality (NEO five-factor inventory) tests. The Wonderlic personnel test is a timed, 50-item cognitive ability measure commonly used in the pre-employment selection context. Wonderlic scores are highly consistent with other well-recognized measures such as the Wechsler Adult Intelligence Scale, the General Aptitude Test Battery, and the Stanford Achievement Test (see, e.g., McKelvie (1989), Hawkins et al. (1990)). The NEO five-factor inventory (Briggs (1992)) is one of the leading psychological scoring systems which 
generates five measures of personality dimensions called "neuroticism," "extraversion," "openness," "agreeableness," and "conscientiousness."

The neuroticism factor "assesses adjustment vs. emotional instability. Identifies individuals prone to psychological distress, unrealistic ideas, excessive cravings or urges, and maladaptive coping responses." Characteristics of the high scorer on this factor include worrying, nervous, emotional, insecure, inadequate, and hypochodriacal. The extraversion factor "assesses quantity and intensity of interpersonal interaction; activity level; need for stimulation; and capacity for joy." Characteristics of the high scorer on this factor include sociable, active, talkative, person-oriented, optimistic, fun-loving, and affectionate. The openness factor "assesses proactive seeking and appreciation of experience for its own sake; toleration for and exploration of the unfamiliar." Characteristics of the high scorer on this factor include curious, broad interest, creative, original, imaginative, and untraditional. The agreeableness factor "assesses the quality of one's interpersonal orientation along a continuum from compassion to antagonism in thoughts, feelings, and actions." Characteristics of the high scorer on this factor include soft-hearted, goodnatured, trusting, helpful, forgiving, gullible, and straightforward. Finally, the conscientiousness factor "assesses the individual's degree of organization, persistence, and motivation in goal-directed behavior. Contrasts dependable, fastidious people with those who are lackadaisical and sloppy." Characteristics of the high scorer on this factor include organized, reliable, hardworking, self-disciplined, punctual, scrupulous, neat, ambitious, and persevering (Costa and McCrae (1992)).

The conventional dictator game experiments were conducted at both Minnesota and Brown using identical protocols and the same experimental teams. These experiments were fashioned in a manner that closely follows the double-blind design of Hoffman et al. (1994) and Eckel 
and Grossman (1996) to assure anonymity both among subjects and between subjects and experimenters. Appendix A contains the instructions given to dictators. Ben-Ner, Kong, and Putterman (2004) and Ben-Ner, Putterman, Kong, and Magan (2004) describe the experiments in more detail.

One-half of the subjects at each site were assigned to the role of dictator and the other half to the role of recipient. Dictators and recipients entered different rooms in separate buildings and were assured explicitly of their anonymity. In addition to the $\$ 15$ participation fee, each participant in the dictator rooms was given an envelope that contained 10 slips of paper and 10 one dollar bills, mixed together - the slips being included so that sending decisions would take the same amount of time to implement, and the resulting envelopes would be of the same thickness, regardless of the amount sent. The decision on how much money and how many slips of paper to retain and to send was made at "privacy stations" fashioned so as to hide the subject from the knee up (thus providing complete privacy for transferring money or paper slips from envelopes to one's own pockets). The envelope containing the slips of paper and/or money was deposited by the subjects in a box. When all subjects completed their decisions, a room assistant brought the box with envelopes to counters who waited outside each room. In the presence of the room assistant, the counters registered the number of dollars included in the money envelope. Room assistants and counters transported the money envelopes to the appointed receiving room and gave them to the room assistant for distribution there.

The written instructions given to dictators included information about their potential recipient. At Minnesota, 22 subjects were told that this person was a female, and 28 were told that this person was a male. At 
Brown, 22 subjects were told that this person was a female; because of the smaller sample size, the 'male' condition was not employed. ${ }^{4}$

\subsection{Hypothetical Dictator Game Experiments}

This experiment was conducted at the University of Minnesota, and was patterned closely after the conventional experiments described above. In this experiment, all subjects ( 220 of them) were assigned to the role of dictator, and were told to imagine that they were given $\$ 10$ to divide between themselves and another person in increments of $\$ 1$, by writing down how much they would give away and how much they would keep so that the total would be $\$ 10$. The subjects were asked to imagine the situation to be as close as possible to a real-life situation, and were given assurances of anonymity. As in the previous experiments, subjects-dictators were given information about the hypothetical person to whom they considered giving hypothetical money. Of the 220 subjects, 20 were told that their potential recipient was a female. Appendix $\mathrm{C}$ contains the instructions to this experiment.

The majority of the subjects/dictators, 200 of them, participated in an experiment that consisted of 91 mini-experiments, insofar as subjects were asked to consider separately sharing the hypothetical $\$ 10$ with 91 different persons. The descriptions were presented in just a few words in a list in which the types of persons followed no particular order. The instructions to this experiment are included in Appendix B. Of these hypothetical or imaginary persons that were described, this paper focuses on two characterizations, male and female (i.e., "giving to male" and "giving

$\mathrm{PT}^{4}$ TPIn both sets of experiments, we collected data that are not pertinent to the present paper. In the conventional dictator game experiments at Minnesota (Brown), 24 (21) subjects were told that they are dividing their $\$ 10$ with a 'person' about whom no further information was provided. In Minnesota, 24 subjects were told that this person was born and raised in Minnesota, and 18 subjects were told that this person has arrived recently to Minnesota. 
to female"). All 220 subjects participated subsequently in additional experiments that do not bear on the subject matter of this paper, and completed the same instruments that were administered in the experiment with actual money.

\section{Analysis}

\subsection{Summary Statistics and Preliminary Analysis}

In Table 1, we present summary statistics for both sets of experiments ("pay" and "no pay" for experiments with and without money, respectively) of the different variables used. In addition to information on amounts sent, we report raw scores dictators earned on NEO agreeableness, conscientiousness, extraversion, neuroticism, and openness scales, and raw scores earned on the Wonderlic personnel test on problem-solving ability.

We combined the data from the two "pay" experiments in the giving-to-females condition at Minnesota and Brown; the average giving in the two experiments differs by $\$ 0.05$, and tests comparing the two distributions justify the pooling. In the "no pay" experiments we combined the data for giving to females by the 200 subjects who participated in the experiment with multiple items with the data for the 20 subjects who gave to females in a single-item experiment; the difference in average giving is $\$ 0.11$, and the pooling is supported by statistical tests.

\section{Table 1, Here}

Clearly, the average dictator is not acting less generously in our dataset when payments are real rather than hypothetical. On the contrary, the amounts sent slightly increase in experiments where real money is 
allocated. Whereas the average amount sent when no money is involved is $\$ 2.70$ (SD of 2.89), it increases to $\$ 3.08$ (SD of 2.52) when subjects allocate actual $\$ 10$. These differences, however, are not economically or statistically significant. An Anova F-statistics test fails to reject the null hypothesis of equal means at accepted significance levels. Equality of medians (Wilcoxon/Mann-Whitney) and variances (adjusted Bartlett statistic) cannot also be rejected. As expected, in an OLS regression of dollar amounts sent on a dummy variable (1 when choices are hypothetical, 0 otherwise), the estimated coefficient is negative but far from being significant (probability of 0.29).

As previously mentioned, in dictator games where players are asked to divide $\$ 5$, Forsythe et al. (1994) reject the "pay hypothesis," stating that the distributions of dictator allocations are identical with and without pay, in favor of the alternative that dictators are more generous when payments are hypothetical (they fail to reject the null, however, on the basis of experimental data collected in one of their two sessions). Our results show that the conclusion (based on aggregated data) that financial incentives in dictator games induce substitution away from behavior considered to be socially desirable is premature. Additional evidence is needed to assist in conclusively establishing the average effect of financial incentives on giving.

The analysis thus far suggests that experimental dictators are neither more nor less selfish when asked to transfer part of a real rather than hypothetical endowment to another powerless subject. However, the evidence cited above documents substantial differences in individuals' behavior and decision-making processes and finds that these differences are associated with differences in cognitive ability and personality characteristics. As a result, any attempt at aggregating across subjects may be misleading. The next Subsection disaggregates the data by controlling for dictators' main personality traits, in addition to their cognitive ability. 
We are unaware of any attempt to study incentive effects at the individual level.

\subsection{Financial Incentives, Individual Differences, and Personality Types}

In this Subsection, we conduct an exploratory analysis of incentive effects in dictator game experiments at the level of the individual subject/dictator. Here, individuals differ on: 1) their cognitive ability measured using the Wonderlic personnel test, and 2) their personality traits - based on scores in the NEO five-factor inventory. In essence, the statistical analysis we provide below questions whether the heterogeneous impact of monetary incentives on dictators' generosity can be reconciled by the corresponding differences in cognition scores and scores on the five personality factors. Estimates reported in Table 2 are based on both OLS and ordered logit estimation. The 200 subjects who participated in the multiple-item hypothetical giving experiments gave to both a female and a male. We follow scholars who work with data generated from multiple responses from the same subjects (e.g., Eckel and Grossman (2003)) and treat the two responses from each of the 200 subjects as panel data, with individual fixed effects being picked up by personality and cognition factors.

\section{Table 2, Here}

PT $^{5}$ TPIn addition to the variables reported in the Table, the estimated specifications include a control for the dictator's and recipient's gender, the five personality and cognitive ability variables, and their interaction with the dictator's gender. For the sake of conciseness, we do not report the corresponding estimates and refer the interested reader to Ben-Ner, Kong, and Putterman (2004) for an elaboration on some of these empirical relations. 
The main message emanating from the Table is that the effects of financial incentives - differences across experimental dictators in allocations of real and hypothetical dollars - are related to individual differences in personality but are independent of the dictator's gender and cognitive ability. More specifically, we find that these differences are related to dictators' scores on two of the five personality traits, agreeableness and extraversion. For the agreeableness variable, the coefficient of the 'no pay' dummy (1 for hypothetical allocations, 0 otherwise) is estimated to be negative (-0.214 and -0.134, in OLS and ordered logit estimation, respectively) and highly significant (probability of 0.3 percent in both cases). In the case of the extraversion variable, an opposite effect is documented. The coefficient of the 'no pay' dummy is estimated to be positive $(0.244$ and 0.158 , in OLS and ordered logit estimation, respectively) and is different from zero at any probability level.

Agreeable dictators (believed to be "fundamentally altruistic") - those who score high on the agreeableness personality scale - are found to downplay their actual contribution when their intentions are elicited; they send more when asked to divide real $\$ 10$ than when the $\$ 10$ are fictional. These agreeable individuals, who are characterized in the psychological literature by straightforwardness, trust, altruism, modesty, tendermindedness, and compliance (the six different facets defining agreeableness, Costa and McCrae (1992)) will be more generous towards recipients lacking any bargaining power when actions have monetary consequences (since amounts kept are added to their final experimental payoff). When hypothetically challenged, knowing that their actions have no real consequences for recipients, agreeable dictators will portray themselves as more self-centered, profit-maximizers than what is subsequently revealed by their actions. They are modest in their speech, but exceed in their actions; they "walk the walk" but do not "talk the talk." 
Extravert dictators - those who score high on the extraversion personality scale - are in stark contrast talking the talk but not walking the walk; their stated intentions poorly predict their actual actions. These extravert individuals, who are characterized in the psychological literature by gregariousness, activity level, assertiveness, excitement-seeking, positive emotions, and warmth (the six different facets defining extraversion) will portray themselves as generous when generosity is costless. Alas, their actions fall short of intentions. When actions bear financial consequences, the generosity of extravert dictators will wane. In this respect, "they have too many high sounding words, and too few actions that correspond with them" (Abigail Adams).

\section{Conclusions}

This paper looked into the possible effects of financial incentives in dictator game experiments. The limited evidence so far suggests that experimental dictators are less generous when endowments are real rather than hypothetical. We challenged this finding and argued more generally that by aggregating across subjects, valuable behavioral information may be lost. To substantiate this claim, we conducted hypothetical dictator game experiments and corresponding experiments played with actual money and partitioned the sample based on collected information on dictators' cognitive ability and five major personality traits.

We concluded that the impact of incentives on dictators' generosity is much more complex than previously thought and in particular varies a great deal across individuals (making the often-used assumption of a fictitious average subject problematic). We were nonetheless successful in relating these individual differences to two of the five personality traits in the NEO five-factor inventory, agreeableness and extraversion. Extravert dictators conformed to the aforementioned evidence - generous whenever 
generosity had no financial consequences, but selfish profit maximizers when real dollars were at stake. However, the shift from fictional to real choices/dollars had a surprisingly different effect on kind, cooperative, unselfish, trustful, and generous experimental dictators. For these individuals, actual contributions exceeded the hypothetical ones. Agreeable dictators downplayed their contributions and revealed their true generosity only when their actions could really influence the well-being of potential recipients.

In summary, we believe the contribution of this work is twofold. First, we provide additional evidence on the potential role of incentives in experimental setups, particularly emphasizing differences at the individual level. Second, we provide evidence on the economic significance of incorporating individual personality differences in order to better understand observed heterogeneities in individuals' choices. This corroborates recent successful attempts to link personality types to behavioral differences across decision-makers in various setups.

\section{References}

Ben-Ner A., Kong F., and Putterman L., 2004, Share and Share Alike? Gender-Pairing, Personality, and Cognitive Ability as Determinants of Giving, Journal of Economic Psychology, 25, 581-589.

Ben-Ner A., Putterman L., Kong F., and Magan D., 2004, Reciprocity in a Two-Part Dictator Game, Journal of Economic Behavior and Organization, 53, 333-352.

Boone C., De Brabander B., and van Witteloostuijn A., 1999, The Impact of Personality on Behavior in Five Prisoner's Dilemma Games, Journal of Economic Psychology, 20, 343-377. 
Brandstatter H., and Guth W., 2000, A Psychological Approach to Individual Differences in Intertemporal Consumption Patterns, Journal of Economic Psychology, 21, 465-479.

Briggs S. R., 1992, Assessing the Five-Factor Model of Personality Description, Journal of Personality, 60, 253-293.

Burks S. V., Carpenter J. P., and Verhoogen E., 2003, Playing Both Roles in the Trust Game, Journal of Economic Behavior and Organization, 51, 195-216.

Camerer C. F., and Hogarth R. M., 1999, The Effects of Financial Incentives in Experiments: A Review and Capital-Labor-Production Framework, Journal of Risk and Uncertainty, 19, 7-42.

Campbell K. W., Goodie A. S., and Foster J. D., 2004, Narcissism, Confidence, and Risk Attitude, Journal of Behavioral Decision Making, 17, 297-311.

Costa P. T. Jr., and McCrae R. R., 1992, NEO-PI-R: Professional Manual, Odessa, FL: Psychological Assessment Resources.

Eckel C., and Grossman P., 1996, Altruism in Anonymous Dictator Games, Games and Economic Behavior, 16, 181-191.

Eckel C., and Grossman P., 2003, Rebate versus Matching: Does How We Subsidize Charitable Contributions Matter?, Journal of Public Economics, 87 (3-4), 681-701.

Fershtman C., and Gneezy U., 2001, Discrimination in a Segmented Society: An Experimental Approach, Quarterly Journal of Economics, 116 (1), 351-377.

Forsythe R., Horowitz J. L., Savin N. E., and Sefton M., 1994, Fairness in Simple Bargaining Experiments, Games and Economic Behavior, 6, 347-369. 
Gunnthorsdottir A., McCabe K., and Smith V., 2002, Using the Machiavellianism Instrument to Predict Trustworthiness in a Bargaining Game, Journal of Economic Psychology, 23, 49-66.

Hawkins K., Faraone S., Pepple J., and Seidman L., 1990, WAIS-R Validation of the Wonderlic Personnel Test as a Brief Intelligence Measure in a Psychiatric Sample, Psychological Assessment, 2, 198-201.

Hoffman E., McCabe K., Shachat K., and Smith V., 1994, Preferences, Property Rights, and Anonymity in Bargaining Games, Games and Economic Behavior, 7, 346-380.

Holm H., 2000, Gender Based Focal Points, Games and Economic Behavior, 32, 292-314.

Hunter K., and Kemp S., 2004, The Personality of e-commerce Investors, Journal of Economic Psychology, 25, 529-537.

Lauriola M., and Levin I. P., 2001, Personality Traits and Risky Decision-Making in a Controlled Experimental Task: an Exploratory Study, Personality and Individual Differences, 31, 215-226.

McKelvie S., 1989, The Wonderlic Personnel Test: Reliability and Validity in an Academic Setting, Psychological Reports, 65, 161-162.

Nyhus E. K., and Pons E., 2004, The Effects of Personality on Earnings, Journal of Economic Psychology, forthcoming.

Sefton M., 1992, Incentives in Simple Bargaining Games, Journal of Economic Psychology, 13, 263-276.

Stanovich K. E., 1999, Who is Rational? Studies of Individual Differences in Reasoning, Mahwah, NJ: Erlbaum. 


\section{A. Dictator Game Experiment with Money, for the 'Sending-to-Male' Condition}

\section{Instructions for the Experiment}

The instructions you are about to read are self-explanatory. No questions will be answered during this experiment. If you have any questions, you should read back through these instructions. Now that the experiment has begun, please do not talk at all.

In this experiment you have been paired with a person. This person is in a different room from yours, room B. You will not be told who this person is either during or after the experiment. Your only information about this person is that he is also a participant in the experiment and that he is a male.

The room in which you are seated is referred to in these instructions as room A. You will notice that there are other persons in the room who are also participating in this experiment. You have not been paired with any of these persons. Two persons in room A - room assistant 1 and room assistant 2 have been chosen to be the facilitators for today's experiment. The room assistants will be in charge of the envelopes as explained below. In addition, room assistant 1 and room assistant 2 will verify that the instructions have been followed as they appear here.

In this experiment, persons in room A, yourself included, will have the opportunity to send in an envelope, some, all, or none of $\$ 10$ to the person they have been paired with in room $\mathrm{B}$. The person in room $\mathrm{B}$ then keeps the money sent to them.

The remainder of these instructions will explain exactly how this experiment is run. The experiment is structured so that no one, including the experimenters and the room assistants, will know your personal 
decision. Since your decision is private, we ask that you not tell anyone your decision either during, or after, the experiment.

The experiment is conducted as follows: Large envelopes were given to you upon entering the room today. Each of these large envelopes contains 4 envelopes. One of the envelopes is small and labeled 'money.' This envelope contains ten (10) one dollar bills and ten (10) blank slips of paper. You should now take out the envelope marked 'money.' Each person assigned to room A will be called, one at a time, by room assistant 1. The person who was called will then go to one of the privacy stations and open the envelope privately inside the privacy station.

Each person in room A must:

1) First open the sealed envelope marked 'money.' You must decide how many dollar bills (if any) and how many blank slips of paper to leave in the small envelope which will be sent to the person you have been paired with. The number of dollar bills plus the number of slips of paper must add up to 10 . You then keep the remaining dollar bills and slips of paper. The money you keep is yours to take from the experiment along with the $\$ 15$ you receive for participating. Examples: (a) leave $\$ 2$ and 8 slips in the small envelope, keep $\$ 8$ and 2 slips; (b) leave $\$ 9$ and 1 slip in the small envelope, keep $\$ 1$ and 9 slips. These are examples only, the actual decision is up to each person. Once you have made your decision regarding the money, you will seal the envelope inside the privacy station, and then place it in the box at the front of the room marked 'return envelopes.'

2) You will then go back to your seat in the room and await further instructions from the experimenter.

After all the small envelopes have been put in the return box, room assistant 2 will transport the box to a recorder, who is in the hallway. With room assistant 2 observing, the recorder will then, one at a time, 
1) open the envelope,

2) record on a blank sheet of paper the number on the envelope and the amount of money in the envelope, and

3) put the money back in the envelope and reseal it, and put the envelope back in the return box.

At this point, room assistant 2 will take the return box to room $\mathrm{B}$ where the money will be distributed. The person you have been paired with is in room B. Each person in room B has also been asked to fill out the questionnaires and given $\$ 15$ to participate. The money will be given to the appropriate person in room $\mathrm{B}$.

At this stage, you will wait for an experimenter to come into the room and give you instructions as to what will happen next. For the moment, please note that your decision regarding the $\$ 10$ in the small envelope is the only decision that you will be asked to make in this experiment.

\section{SUMMARY:}

1) You have been paired with a person from another room. That person is a male.

2) You need to decide how much of $\$ 10$ you will send to this person.

3) Once you have made your decision regarding how much money to send, you should put the envelope in the box marked 'return envelopes,' return to your seat and await further instructions.

4) No participant in the experiment, including the person with whom you have been paired in Room B, the room assistants, and the experimenters, will know the decision made by you as an identifiable individual. You will not be told and will have no way of knowing the identity of the person in Room B with whom you have been paired. 


\section{B. Simulated Dictator Game Experiment without Money - Giving to a Variety of Types of Persons}

Imagine yourself in a situation in which you are given \$10, which you can keep to yourself or give to another person, all or any portion of it. You may give money only in increments of $\$ 1$. We are asking you to consider giving money to different persons, one at a time. That is, each time you are given $\$ 10$, which you can divide between yourself and another person. Each person is described in the table provided below. When making your decision, please consider only the information given on each line.

Please imagine the situation to be as close as possible to a real-life situation. Remember, all of your answers are entirely anonymous and the researchers have no way of linking them to you or to anybody else in this experiment.

Please indicate in the space provided the amount you give and the amount you keep; make sure that the amount given to the other person and the amount you keep for yourself add up to $\$ 10$.

Here are a few examples. Suppose that the other person is someone who listens to Broadway musicals - this is the only information you have about the other person. Assume that you decide to give $\$ 0$, thus keeping $\$ 10$. This decision should be recorded as indicated in the first line of the examples table shown below. Alternatively, suppose that the other person is your next-door neighbor (and that's all you know about this person), and you decide to give $\$ 2$ and keep $\$ 8$. This decision should be recorded as indicated in the second line of the examples table. As a final example, suppose that the other person is someone named James (again, this is the only information you have about the other person), and you decide to give 
$\$ 10$ and keep $\$ 0$. This decision should be recorded as indicated in the third line of the examples table.

\section{Examples table}

\begin{tabular}{|l|c|c|c|}
\hline The other person... & $\begin{array}{c}\text { Money you give to } \\
\text { this person }\end{array}$ & $\begin{array}{c}\text { Money you keep to } \\
\text { yourself }\end{array}$ & Total \\
\hline \hline Listens to Broadway musicals & $\$ 0$ & $\$ 10$ & $\$ 10$ \\
\hline \hline Is your next door neighbor & $\$ 2$ & $\$ 8$ & $\$ 10$ \\
\hline \hline Is named James & $\$ 10$ & $\$ 0$ & $\$ 10$ \\
\hline
\end{tabular}

These are only hypothetical examples, and the decision how much to give is of course entirely yours.

The experiment begins here. You have $\$ 10$ that you can keep to yourself, or give to another person, all or any portion of it in increments of $\$ 1$. Each line describes a different person. The only thing you know about this person is the information given on that line. Please consider each person separately. Write the amount of money you give to the other person and the amount to keep for yourself in the space provided.

\begin{tabular}{|c|c|c|c|}
\hline The other person... & $\begin{array}{c}\text { Money you give to this } \\
\text { person }\end{array}$ & $\begin{array}{c}\text { Money you keep to } \\
\text { yourself }\end{array}$ & Total \\
\hline Is from a small family & & & $\$ 10$ \\
\hline Listens to bluegrass music & & & $\$ \$ 10$ \\
\hline $\begin{array}{l}\text { Speaks English and additional } \\
\text { languages }\end{array}$ & & & $\$ \$ 10$ \\
\hline Was born and raised in MN & & & $\$ 10$ \\
\hline
\end{tabular}

[many other characterizations follow] 


\section{Simulated Dictator Game Experiment without Money - Giving to a Female}

Imagine yourself in a situation in which you can keep or give to another person, all or any portion of $\$ 10$. This person is a female. You may give money only in increments of $\$ 1$. For example, you can give $\$ 0$ and keep $\$ 10$, or give $\$ 2$ and keep $\$ 8$, or give $\$ 8$ and keep $\$ 2$. These are only hypothetical examples, and the decision of how much to give is entirely yours.

Please imagine the situation to be as close as possible to a real-life situation. Remember, all of your answers are entirely anonymous and the researchers have no way of linking them to you or to anybody else in this experiment.

Your decision is to give $\$ \$_{--}$to this female and to keep $\$$ yourself, for a total of $\$ 10$. 


\section{Tables}

\section{Table 1}

\section{Summary Statistics}

\begin{tabular}{|l|c|c|c|c|}
\hline & Mean-"pay" & SD-"pay" & Mean-"no-pay" & SD-"no-pay" \\
\hline \hline Send & 3.08 & 2.52 & 2.70 & 2.89 \\
\hline Agreeableness & 31.93 & 5.96 & 30.95 & 5.51 \\
\hline Conscientiousness & 30.59 & 6.45 & 31.13 & 6.18 \\
\hline Extraversion & 30.79 & 7.26 & 30.84 & 6.36 \\
\hline \hline Neuroticism & 23.59 & 8.46 & 22.13 & 7.63 \\
\hline Openness & 31.77 & 6.39 & 29.32 & 6.49 \\
\hline Cognition & 28.34 & 5.76 & 28.16 & 5.71 \\
\hline \# Obs. & 72 & & 420 \\
\hline
\end{tabular}

The Table presents summary statistics on amounts sent by dictators in experiments with money ("pay") and experiments without money ("no-pay"); raw scores dictators earned on NEO agreeableness, conscientiousness, extraversion, neuroticism, and openness scales; and raw scores earned on Wonderlic personnel test on problem-solving ability ("Cognition"). 72 (220) subjects participated in "pay" ("no pay") experiments. The number of observations for the NEO factors and cognitive ability measure is 220 . 


\section{Table 2}

\section{Estimation Results}

\begin{tabular}{|l|c|c|}
\hline & OLS & Ordered Logit \\
\hline \hline Constant & 5.750 & \\
& $(0.159)$ & \\
\hline No Pay Dummy & -4.941 & -3.482 \\
& $(0.251)$ & $(0.194)$ \\
\hline No Pay Dummy x gender & -0.298 & -0.279 \\
& $(0.727)$ & $(0.598)$ \\
\hline No Pay Dummy x a & -0.214 & -0.134 \\
& $(0.003)$ & $(0.003)$ \\
\hline No Pay Dummy x c & 0.020 & 0.020 \\
& $(0.725)$ & $(0.573)$ \\
\hline No Pay Dummy x e & 0.244 & 0.158 \\
& $(0.000)$ & $(0.000)$ \\
\hline No Pay Dummy x $n$ & 0.094 & 0.053 \\
& $(0.057)$ & $(0.086)$ \\
\hline No Pay Dummy x $O$ & -0.001 & 0.002 \\
& $(0.987)$ & $(0.952)$ \\
\hline No Pay Dummy x cog & 0.041 & 0.023 \\
& $(0.549)$ & $(0.579)$ \\
\hline \# Obs. & 491 & 491 \\
\hline Adjusted R-squared & 0.082 & \\
\hline Pseudo R-squared & & 0.035 \\
\hline I & & \\
\hline
\end{tabular}

The Table reports OLS and ordered logit estimation results of the model in Subsection 3.2. Transfers of experimental dictators are related to the dictator's gender (gender, 1 for male dictators); raw scores dictators earned on NEO agreeableness (a), conscientiousness (c), extraversion (e), neuroticism (n), and openness (o) scales; and raw scores earned on Wonderlic personnel test on problem-solving ability $(\operatorname{cog})$. The 'no pay' dummy equals 1 for hypothetical contributions. In addition to the variables reported in the Table, the estimated specifications include a control for the dictator's and recipient's gender, the five personality and cognitive ability variables, and their interaction with the dictator's gender. The corresponding estimates are not reported here. The number of observations is 491 since we do not have gender information on one of the participants. Probabilities are in parentheses. 